\title{
PREVALENCE OF IODINE INTAKE INADEQUACY IN ELDERLY BRAZILIAN WOMEN. A CROSS-SECTIONAL STUDY
}

\author{
S.A. DESTEFANI', J.E. CORRENTE², S.A.R. PAIVA ${ }^{3}$, G.M.F.S. MAZETO ${ }^{4}$
}

\begin{abstract}
1. MSc. Professor, Nutrition Department, Paulista University (UNIP), Bauru, São Paulo, Brazil; 2. PhD. Professor, Biostatistics Department, Institute of Biosciences, Sao Paulo State University (Unesp), Botucatu, Brazil; 3. PhD. Professor, Internal Medicine Department, Botucatu Medical School, Sao Paulo State University (Unesp), Botucatu, Brazil;

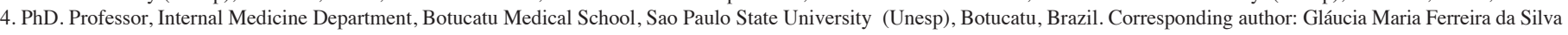

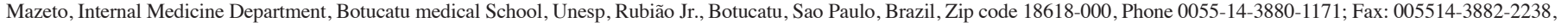
E-Mail: gmazeto@fmb.unesp.br
\end{abstract}

\begin{abstract}
Background/Objectives: Inadequate iodine intake is still a problem in various regions of the world, and limited data exist regarding the ingestion of iodine in elderly people. We investigated the prevalence of iodine intake inadequacy in a group of elderly women living in a region of Brazil considered to be iodinesufficient. Design and setting: Cross-sectional study conducted in the public healthcare system of Bauru, São Paulo, Brazil. Methods: We evaluated 135 elderly women (average age of 68.2 years) who participated in a program of assistance to the elderly with respect to iodine intake through two 24-hour recalls using a nutritional computer program. The women were also evaluated with respect to serum levels of free thyroxin (FT4) and thyrotropin (TSH) and were classified as euthyroid, hypothyroid or hyperthyroid. Results: The average iodine intake of the group was $100.7 \pm 39.2 \mu \mathrm{g}$. Twenty-nine patients $(21.5 \%)$ presented thyroid dysfunction: 27 (20\%) had hypothyroidism, and two (1.5\%) had hyperthyroidism. The average iodine intake of the patients with hypothyroidism and euthyroidism was $92.7 \mu \mathrm{g}$ and $101.7 \mu \mathrm{g}$, respectively. The prevalence of iodine intake inadequacy, considering the co-variables of age, race, income, body mass index, TSH, FT4 and arterial hypertension, was 51\%, $48 \%$ and $66 \%$ in the general, euthyroid and hypothyroid patients, respectively. Conclusion: We concluded that high prevalence of iodine intake inadequacy was present in this group of elderly women living in a region of Brazil considered to be iodine-sufficient.
\end{abstract}

Key words: Elderly nutrition, hyperthyroidism, hypothyroidism, iodine, nutrients.

\section{Introduction}

Iodine is an essential micronutrient for the synthesis of thyroid hormones, and its nutritional status is an important factor in the dysfunction of the thyroid gland (1).

Insufficient intake of iodine is still a problem in various regions of the world $(2,3)$. Public health programs have attempted to minimize this problem, and in recent decades, many countries have been able to substantially elevate the intake of this nutrient through the fortification of food with iodine. In Brazil, a salt iodation policy has been in place since 1953 to promote the appropriate consumption of iodine (4). In recent decades, the recommended maximum fortification of salt with iodine has varied between $60 \mathrm{mg}$ and $100 \mathrm{mg}$ of iodine $/ \mathrm{kg}$ of salt, according to evidence regarding excesses or deficiencies of iodine (5-7). Although the current limit is $60 \mathrm{mg} / \mathrm{kg}$ of salt (4), in certain regions of the country, excessive levels of urinary iodine have been reported in some groups of people, such as children (8), adults who live in metropolitan areas and people who have heart conditions $(1,5)$. However, these findings do not represent all population groups and should not be generally extrapolated to the country's population.

Aging is related to increased morbidity, and members of aged populations frequently present restrictions related to foods and additives. These food restrictions can influence the inflow of various nutrients and trace elements, one of which is iodine. In fact, in regions considerate insufficient for this nutrient, the prevalence of insufficient intake appears to be particularly elevated in elderly women. However, few studies are available regarding the ingestion of iodine in elderly people, even in regions that are considered to be iodine sufficient (2).

The aim of present study was to investigate the prevalence of iodine intake inadequacy in a group of elderly women living in a region of Brazil considered to be iodine-sufficient.

\section{Methods}

We evaluated 135 elderly patients with respect to iodine intake with assistance from the City Program of Assistance to the Elderly of Bauru City in Sao Paulo State, Brazil. The study was approved by the Ethics Committees of Botucatu Medical School-São Paulo State University - Unesp (11/3/2008) and of Studies and Research of the Municipal Health of Bauru $(9 / 16 / 2008)$. The patients were evaluated with regard to race, age (years), weight $(\mathrm{kg})$, height $(\mathrm{m})$, body mass index (BMI; $\mathrm{kg} / \mathrm{m}^{2}$ ), income (as multiples of the minimum wage) and the diagnosis of arterial hypertension and thyroid dysfunction. Hypertension was considered a co-variable due to dietary salt restriction usually prescribed for these patients.

Iodine intake was evaluated through two 24-hour recalls, with an intervening gap of 30 days. The food amount, given in kitchen measures, was transformed into grams and input into the program DietPro5i ${ }^{\circledR}$ (DietPro, Viçosa, Brazil), which calculated the intake amount of iodine. As iodinated salt is one of the main sources of iodine in Brazil, the amount of salt ingested by the patients was evaluated. Salt intake included 
both added salt and salt present in prepared or packaged food. In Brazil, $93 \%$ of iodine salt samples sold to the public were found to contain $15-45 \mathrm{mg} / \mathrm{kg}$ iodine, with most containing $20-30 \mathrm{mg} / \mathrm{kg}$ (9). Analyses of table salt samples obtained in towns near the city where this study was conducted, showed average levels of iodine of $22-27 \mathrm{mg} / \mathrm{kg}$ of salt $(10,11)$. Thus, for this study, each gram of salt was considered to contain $25 \mu \mathrm{g}$ of iodine. According to the DRI (dietetic recommended intake), the daily intake recommendation was $95 \mu \mathrm{g}$ of iodine (estimated average requirement; EAR) $(12,13)$. The EAR cutoff point was applied to estimate the prevalence of iodine intake inadequacy $(14,15)$. To apply this method, information on the usual intake was needed to attenuate intraindividual variability (16). When using diet recalls or registers, the usual intake is estimated by applying statistical methods (17).

Body weight was measured on a platform-type scale, and height was estimated using a vertical stadiometer that was coupled to the scale. Following the measurement of weight and height, the BMI was estimated by Quetelet's formula. The diagnosis of arterial hypertension was determined by checking the patient's medical records.

Thyroid abnormalities were diagnosed based on the levels of thyroid stimulating hormone (TSH) and free thyroxine (FT4), which were measured by chemiluminescence (DPC, Los Angeles, United States) on two different occasions. Thyroid function was classified as euthyroid (normal) when TSH and FT4 were within the normal reference ranges $(0.4-4.0 \mathrm{mIU} / \mathrm{L}$ and $0.8-1.9 \mathrm{ng} / \mathrm{dL}$, respectively), as hypothyroid when TSH was elevated and as hyperthyroid when TSH was suppressed. Hypothyroidism and hyperthyroidism were considered to be overt when the FT4 level was not within the normal range or subclinical when the FT4 level was normal.

In addition to the aforementioned statistical methods for estimating the prevalence of nutrient iodine intake inadequacy $(14,15)$, a descriptive analysis was performed and Student's t-test was used to compare the average iodine intake in hypothyroid and euthyroid patients. Statistical analyses were performed at a significance level of 0.05 .

\section{Results}

The studied group presented an average age of 68 years and mostly white skin color, with an average monthly income of 1.5 times the minimum wage and an average BMI classified as overweight. Sixty patients $(44.4 \%)$ presented hypertension, and $29(21.5 \%)$ presented thyroid dysfunction, of which $27(20 \%)$ had hypothyroidism (three with overt hypothyroidism) and two (1.5\%) had hyperthyroidism (one with overt hyperthyroidism) (Table 1).

The average ( \pm standard deviation) iodine intake of the group was $100.7 \pm 39.2 \mu \mathrm{g} / \mathrm{day}$. The average iodine intake of hypothyroid and euthyroid patients was $92.7 \pm 31.2 \mu \mathrm{g} /$ day and $101.7 \pm 40.5 \mu \mathrm{g} /$ day, respectively $(\mathrm{p}=0.29)$. The two patients with hyperthyroidism presented an average iodine intake of $154.0 \mu \mathrm{g}$.
The prevalence of iodine intake inadequacy was $44 \%, 42 \%$ and $57 \%$ in the general, euthyroid and hypothyroid patients, respectively. Adjusting for the co-variables age, race, income, BMI, TSH, FT4 and arterial hypertension, the prevalence was $51 \%, 48 \%$ and $66 \%$, respectively. In the hypothyroid patients, without correlation with the co-variables, a constant pattern of iodine intake by each patient $(p=0.66)$ and by the group $(\mathrm{p}=0.61)$ was observed. In the remaining groups, no constant pattern was observed regarding iodine intake by each patient or each group (Table 2).

Table 1

General data of 135 elderly patients from Bauru City, Sao Paulo state, Brazil

\begin{tabular}{lc}
\hline Data & Patients \\
\hline & \\
Age $($ years $) \dagger$ & $68.23 \pm 7.86$ \\
Caucasian N $(\%)$ & $107(79.3)$ \\
Income $($ multiples of the minimum wage $) \dagger$ & $1.5(0 ; 15)$ \\
BMI $(\mathrm{kg} / \mathrm{m} 2) \dagger$ & $27.8 \pm 5.6$ \\
Iodine intake* $(\mu \mathrm{g}) \dagger$ & $100.7 \pm 39.2$ \\
FT4 $(\mathrm{ng} / \mathrm{dL}) \dagger$ & $1.1 \pm 0.2$ \\
TSH $(\mathrm{mUI} / \mathrm{L}) \ddagger$ & $2.2(0.0 ; 19.1)$ \\
Presence of hypertension $\mathrm{N}(\%)$ & $60(44.4)$ \\
Presence of thyroid dysfunction $\mathrm{N}(\%)$ & $29(21.5)$ \\
\hline
\end{tabular}

$\mathrm{N}$ : number; BMI: body mass index; $\mathrm{kg}$ : kilogram; $\mathrm{m}$ : meter; $\mu \mathrm{g}$ : microgram; $\mathrm{ng}$ / dL: FT4: free thyroxin; nanograms per deciliter; TSH: thyroid stimulating hormone; $\mathrm{mUI} / \mathrm{L}$ : milliunits per liter. * According to the DRI (recommended dietetic intake), the recommendation daily intake for the group evaluated is $95 \mu \mathrm{g}$ (estimated average requirement- EAR). $\dagger:$ mean \pm standard deviation. $\neq$ : median (minimum; maximum).

\section{Table 2}

Prevalence of iodine intake inadequacy according to the dietary reference intakes (EAR: $95 \mu \mathrm{g}$ ), adjusting or not for the co-variables age, race, income, BMI, TSH, FT4 and hypertension

\begin{tabular}{lccc}
\hline Patients & $\begin{array}{c}\text { Prevalence of } \\
\text { Inadequacy (\%) }\end{array}$ & $\mathbf{S}^{2} \mathbf{b} *$ & $\mathbf{S}^{2} \mathbf{w} *$ \\
& p-value & p-value \\
\hline General & 44 & 0.0000 & 0.0000 \\
Euthyroid & 42 & 0.0000 & 0.0000 \\
Hypothyroid & 57 & 0.6607 & 0.6065
\end{tabular}

Considering the covariates of age, race, income, BMI, TSH, FT4 and hypertension

\begin{tabular}{llll} 
General & 51 & 0.0000 & 0.0000 \\
Euthyroid & 48 & 0.0000 & 0.0000 \\
Hypothyroid & 66 & 0.0000 & 0.0484 \\
\hline
\end{tabular}

EAR: estimated average requirement; $\mu \mathrm{g}$ : microgram; BMI: body mass index; FT4: free thyroxin; TSH: thyroid stimulating hormone. ${ }^{*} \mathrm{~S}^{2} \mathrm{~b}$ : interpersonal variation (considered indicative of the absence of a pattern of constant consumption of iodine by each individual patient when significant); ** $\mathrm{S}^{2} \mathrm{w}$ : intrapersonal variability (considered indicative of a lack of iodine consumption by the group of patients when significant). 


\section{JNHA: NUTRITION}

\section{Discussion}

In this study, the 24-hour recalls showed that although the average iodine intake was near the recommended value for the groups, there was high prevalence of iodine intake inadequacy, particularly in hypothyroid patients. Dietary insufficiency of iodine still represents a public health problem in many countries and is of particular concern in vulnerable groups, such as pregnant or lactant women, infants and elderly $(2,3)$. More than $20 \%$ of the adult population of Finland, the adult and elderly population of Germany and the elderly population of Ireland (female only) had an iodine intake below the recommended values (2). However, the prevalence of iodine insufficiency can vary greatly, depending on the iodine content of the food of the studied regions, the presence of fortification programs and the dietary characteristics unique to each population group. Some specific dietary patterns, such as the Mediterranean diet, may be associated with favorable iodine intake (18).

Nutritional status of iodine has been evaluated using urinary iodine quantification in addition to other indirect methods, such as hormonal dosage tests and ultrasound of the thyroid (1, 5, 8,11 ). Urinary iodine (UI) represents a good indicator of the recent ingestion of iodine, as $90 \%$ of ingested iodine is expelled through the urine (19). Currently, the UI excretion is the more reliable method for estimation of individual iodine status. However, although the methodology is reliable, it is costly and not available at all centers.

Evaluation of the ingestion of iodine, such as the quantification of the prevalence of inadequacy, could alert to the possibility of iodine insufficiency in specific population groups. The prevalence of nutrient inadequacy in a specific group of people represents the proportion of people whose consumption is below the EAR and can be used to establish hypotheses regarding the positive or negative connections between dietary plans and diseases $(13,20)$. Between the advantages of the method, can be said that, while the UI evaluate at a single time point, the estimation of the prevalence of inadequacy is based on two 24-hour recalls performed at different time points, which reduces the intrapersonal and interpersonal variation in the measurement. However, no standard is currently available for adequacy studies of micronutrients, which can lead to different estimates of the prevalence of inadequacy for these micronutrients (21). In some European countries, for example, the prevalence of iodine intake inadequacy in women 64 years of age or older using an EAR of $100 \mu \mathrm{g} /$ day may vary from $9 \%$ to $53 \%$ (2).

In Brazil, a recent study evaluated the prevalence of intake inadequacy of various micronutrients according to age and geographical region (22). However, iodine was not included in the results. Considering a likely iodized salt intake in the Brazilian population of $9.6 \mathrm{~g}$ of salt/person/day, which is above average relative to industrialized countries and much higher than the $5 \mathrm{~g} /$ person/day intake recommended by the Health
World Organization, the iodine intake in Brazil is likely to be higher than the recommended intake of $150 \mathrm{mcg} /$ day $(23,24)$. However, the truth is that, even in regions considered sufficient for iodine because of its fortification in food or because of geographical characteristics, little is known about iodine intake in some population groups. We unexpectedly observed, at least in this group of elderly women from a region that is considered to be iodine-sufficient, an high prevalence of dietary iodine inadequacy, especially in women who had hypothyroidism. Thus, the ongoing monitoring of population iodine status remains crucially important, and particular attention may need to be paid to monitoring the status of vulnerable populations (25).

This study has some limitations, such as the tools used for data collection, which may be subject to underreporting, and the reference values used, which may not be relevant for the population group evaluated. Moreover, it is inconvenient to measure iodine intake as parameter of iodine supply, because of uncertain absorption due to dietary goitrogens, such as fluorides, contaminated water or thiocyanates. Thus, the lack of UI data is a significant limitation. However, the findings reported herein highlight the need for a thorough evaluation of specific population groups. Therefore, considering that deficiency or excess of iodine is detrimental and that iodine sufficiency depends on adequate nutritional ingestion, strategies for the diagnosis and intervention of iodine insufficiency, or excess, are clearly feasible and must be implemented. There is need for ongoing monitoring of iodized salt in order to prevent excess as well as insufficient iodine nutrition, and will be essential to coordinate interventions designed to reduce population sodium intake with salt iodization programs in order to maintain adequate levels of iodine nutrition as salt intake declines $(3,26)$.

We can concluded from this study that high prevalence of iodine intake inadequacy was present in this group of elderly women living in a region of Brazil considered to be iodine-sufficient. New studies in similar population groups are necessary to confirm the findings reported herein.

Acknowledgments: Financial support: The present study was supported by a grant from Research Support Foundation of the State of Sao Paulo (Fundação de Amparo à Pesquisa do Estado de São Paulo, FAPESP; process number 2011/06164-0) and Foundation for the Development of UNESP (Fundação para o desenvolvimento da Unesp, Fundunesp; process number 00133/2010 - DFP). This work was presented in 36th Annual Meeting of the European Thyroid Association as a panel, in Pisa, Italy, in September 2012.

Conflicts of Interest: The authors declare no conflict of interest for this study.

Ethical standards: This study followed the principles of the Declaration of Helsinki and was approved by the Ethics Committees of Botucatu Medical School-São Paulo State University - Unesp (11/3/2008) and of Studies and Research of the Municipal Health of Bauru (9/16/2008). Signed, informed consent was obtained for all participants.

\section{References}

1. Camargo RY, Tomimori EK, Neves SC, et al. Thyroid and the environment: exposure to excessive nutritional iodine increases the prevalence of thyroid disorders in Sao Paulo, Brazil. Eur J Endocrinol 2008;159(3):293-299.

2. Viñas BR, Barba LR, Ngo J, et al. Projected prevalence of inadequate nutrient 


\section{PREVALENCE OF IODINE INTAKE INADEQUACY IN ELDERLY BRAZILIAN WOMEN}

intakes in Europe. Ann Nutr Metab 2011,59(2-4): 84-95

3. Pearce EN, Andersson M, Zimmermann MB. Global iodine nutrition: where do we stand in 2013? Thyroid 2013;23(5):523-528.

4. Medeiros-Neto G. Iodine nutrition in Brazil: where do we stand? Arq Bras Endocrinol Metab 2009;53(4):470-474.

5. Duarte GC, Tomimori EK, Camargo RY, et al. The prevalence of thyroid dysfunction in elderly cardiology patients with mild excessive iodine intake in the urban area of São Paulo. Clinics 2009;64(2):135-142.

6. Pretell EA, Delange F, Hostalek U, et al. Iodine nutrition improves in Latin America. Thyroid 2004;14(8):590-599.

7. Medeiros-Neto G. The salt iodization program in Brazil: a medical and politica conundrum. IDD Newsletter 2000;3:31-32.

8. Carvalho AL, Meirelles CJ, Oliveira LA, Costa TM, Navarro AM. Excessive iodine intake in schoolchildren. Eur J Nutr 2012;51(5):557-562.

9. Agência Nacional de Vigilância Sanitária. Resultado do Monitoramento do Teor de Iodo no sal Ano: 2010. Available from: http://portal.anvisa.gov.br/wps/ wcm/connect /4e8dfc004bc8a35aabe2fbbc0f9d5b29/Relatorio_pro_Iodo_2010. pdf?MOD=AJPERES. Accessed 18 April 2013

10. Oliveira AA, Nóbrega JA, Pereira-Filho ER. Avaliação de ICP OES com configuração axial ou radial para determinação de iodo em sal de cozinha. Quim Nova 2012;35(7):1299-1305.

11. Alves ML, Duarte GC, Navarro AM, Tomimori EK. Ultrasonographic evaluation of the thyroid, determination of ioduria and iodine concentration in kitchen salt used by schoolchildren in Ribeirão Preto, São Paulo, Brazil. Arq Bras Endocrinol Metabol 2010;54(9):813-818.

12. Institute of Medicine. Dietary Reference intakes: Applications in Dietary Assessment National Academies Press; 2000. 289 pp.

13. Fisberg RM, Marchioni DML, Slater B. Nutritional Recomendations. In: Fisberg RM, Slater B, Marchioni DML, Martini LA. Food Surveys - Methods and Cientifical Bases. 1st ed. Manole; 2005. pp. 190-236.

14. Tooze JA, Midthune D, Dodd KW, et al. A new statistical method for estimating the usual intake of episodically consumed foods with application to their distribution. J Am Diet Assoc 2006, 106(10):1575-1587.
15. Dodd KW, Guenther PM, Freedman LS, et al. Statistical methods for estimating usual intake of nutrients and foods: a review of the theory. J Am Diet Assoc 2006;106(10):1640-1650.

16. Carriquiry AL. Assessing the prevalence of nutrient inadequacy. Public Health Nutr 1999;2(1):23-33

17. Hoffmann K, Boeing H, Dufour A, et al. Estimating the distribution of usual dietary intake by short-term measurements. Eur J Clin Nutr 2002;56(S2):S53-S62.

18. Serra-Majem L, Bes-Rastrollo M, Román-Viñas B, et al. Dietary patterns and nutritional adequacy in a Mediterranean country. Br J Nutr 2009;101(S2):S21-S28.

19. Zimmermann MB. Methods to assess iron and iodine status. Br J Nutr 2008;99(S3):S2-S9.

20. Slater B, Marchioni D, Fisberg MR. Estimating the prevalence of inadequate nutrient intake. Rev Saude Publica 2004;38(4):599-605.

21. Tabacchi G, Wijnhoven TM, Branca F, et al. How is the adequacy of micronutrient intake assessed across Europe? A systematic literature review. Br J Nutr 2009;101: S29-36.

22. Researches and Family Budgets - POF 2008-2009. Brazilian Institute of Geography and Statistics. Available from: http://www.ibge.gov.br/home/estatistica/populacao/ condicaodevida/pof/2008_2009_analise_consumo/defaulttab_pdf_energia.shtm. Accessed 22 February 2013.

23. XI Common Share Meeting of the Interinstitutional Committee of Prevention and Controlo $f$ the Disturbs and Deficiency by Iodine Brasília/DF, 2007. Available from: http://189.28.128.100/nutricao/docs/iodo/ata1liodo.pdf. Accessed 8 April 2013.

24. World Health Organization. Assessment of iodine deficiency disorders and monitoring their elimination: a guide for programme managers. 3rd ed. World Health Organization; 2007.98 pp.

25. Ristić-Medić D, Novaković R, Glibetić M, Gurinović M. EURRECA-Estimating Iodine Requirements for Deriving Dietary Reference Values. Crit Rev Food Sci Nutr 2013;53(10):1051-1063.

26. Hendriksen MA, van Raaij JM, Geleijnse JM, et al. Monitoring salt and iodine intakes in Dutch adults between 2006 and 2010 using $24 \mathrm{~h}$ urinary sodium and iodine excretions. Public Health Nutr 2014;17(7):1431-1438. 